\title{
Importância da gênese documental para identificação de acervos fotográficos
}

Importance of documentary genesis for the identification of photographic collections

Telma Campanha de Carvalho MADıo (1) y Mariângela Spotti Lopes (2)

Universidade Estadual Paulista Júlio de Mesquita Filho, UNESP, Departamento de Ciência de Informação, Av. Hygino Muzzi Filho, 737, Campus Universitário, CEP. 17525-900, Marília, SP, Brasil, Caixa-Postal: 421 (1) telmaccarvalho@marilia.unesp. br. (2) fujita@marilia.unesp. br

\begin{abstract}
Resumen
La fragilidad del soporte y el gran interés imagético que despiertan los acervos fotográficos, muchas veces conllevan grandes perjuicios en el momento de identificación y organización del material. La preocupación con el rescate, preservación y difusión de la memoria histórica y académica de una universidad, se hace presente en el proyecto "Memorial fotográfico de la FFC". Se enfatizan los acontecimientos importantes de la trayectoria académica que comprende el periodo de 1959 a 1999, por medio de la digitalizción y descripción de las fotografías más significativas. Para una organización y transferencia de esa material para el Archivo Central de la Universidad, intentamos mantener la procedencia de esa documentación con el propósito de no perder su historicidad y formación. El proyecto a partir de ese momento se desmembró en dos frentes de investigación: el primero realacionado con la selección de los términos y métodos para representación descriptiva y digitalización de las fotografías; y el segundo con el trabajo bibliográfico, de legislación y encuesta a de los profesionales que trabajaron con los documentos para la identificación de la génesis documental. Como resultado se describieron y digitalizaron 2220 fotografías distribuidas en 57 series documentales.
\end{abstract}

Palabras clave: Acervos fotográficos. Identificación. Organización archivística.

\section{Introdução}

A fotografia, ao documentar um fato, registra uma compreensão histórica por meio da leitura da imagem relacionando o acontecimento com a produção do conhecimento. $O$ processo contínuo no registro da memória histórica por meio de uma linguagem de imagens deve ser aplicado e efetivado na disseminação deste conhecimento.

A imagem fotográfica, aliada ao documento impresso, remete para os aspectos mais prementes da representação da informação no

\begin{abstract}
The fragility of the support and the high interest in images that photographic collections arouse often entail large losses at the time of identifying and organizing the material. Thus, the concern with the rescue, preservation and dissemination of the historical and academic memory of a university located in a countryside city in the State of Sao Paulo, Brazil, through photographic images, is present in the project "Photographic Memorial of FFC", that emphasizes the important events of the academic trajectory which covers the period from 1959 to 1999 through the scanning of the most important photographs as well as their descriptive representation. In order to organize and transfer such material to the Central Archive of the University, we tried to keep the origin of those documents not to lose their historicity and formation. From that moment, the project was divided into two research fronts: the first one involved with the discussions of terms and methods of descriptive representation and scanning photos; and the other one was related to identify the documentary genesis through historical and legislation surveys, and the collection of testimonies of the professionals who worked with the documents. As a result, 2220 photographs distributed on 57 documentary series were scanned and described.
\end{abstract}

Keywords: Photographic collection. Identification. Archive organization.

contexto histórico que a produziu, possibilitando fazer uma nova abordagem acerca da evolução destes registros históricos.

A fragilidade do suporte e o grande interesse imagético que despertam os acervos fotográficos, muitas vezes, acarretam grandes prejuízos no momento de identificação e organização do material.

Nesse sentido, o acervo fotográfico da Faculdade de Filosofia e Ciências (FFC) da Universidade Estadual Paulista (UNESP) do Campus de Marília acumulado no decorrer de sua trajetória acadêmica e administrativa no período de 1959 
a 1999 será tomado como parâmetro para a discussão teórica e metodológica sobre a importância da gênese documental para a identificação de acervos fotográficos.

No bojo dessa discussão insere-se a própria trajetória da identificação e organização do acervo fotográfico que teve seu início a partir da iniciativa de desenvolvimento do Projeto de Extensão "A memória acadêmica em imagens fotográficas: análise de conteúdo e digitalização de fotografias" (1) com os objetivos de: organizar por assuntos específicos as fotografias da trajetória acadêmica no interior paulista da Faculdade de Filosofia e Ciências da Unesp no período de 1959 a 1999; propiciar a recuperação adequada para organização de exposições fotográficas a fim de divulgar a memória acadêmica da universidade pública estadual no interior paulista; preservar de forma digital a memória fotográfica para melhor acesso e uso da imagem e conservação da fotografia original (Fujita et al., 2004).

A preocupação primordial desse projeto concentrava-se na busca do estabelecimento de procedimentos para o tratamento das imagens fotográficas propiciando a recuperação, preservação, registro e a guarda destes documentos com a finalidade de torná-los acessíveis.

Assim, o projeto iniciou-se pelos procedimentos de organização, identificação e guarda dos documentos e teve seqüência na representação descritiva e análise de conteúdo, em abordagem metodológica da Biblioteconomia, para tornar acessível a recuperação das fotografias.

As fotografias da Faculdade de Filosofia e Ciências trabalhadas nesse projeto foram, dessa forma, primeiramente processadas segundo as normas da análise documentária, utilizada comumente pela Biblioteconomia. Ao pretender-se realizar sua identificação arquivística, atentamos para a necessidade de pensarmos o que seria essa documentação dentro de uma organicidade maior, no caso a Faculdade, como elas foram acumuladas ao longo do tempo e qual a intencionalidade de sua produção.

A organização arquivística e a descrição justificam-se pela relevância da memória universitária e também pelo papel que a fotografia assume como fonte variada e rica para a pesquisa. A fotografia há muito vem sendo usada como documento, mas por ter seu princípio na fixação da realidade, diversidade no seu uso e fragilidade dos suportes, vem sendo tratada como documentação especial ou especializada, muitas vezes separada do restante da documentação, causando danos à sua identificação e retirandoa de sua produção original.
Nossa proposta em identificar e estudar a gênese documental do acervo de fotografias da Faculdade de Filosofia e Ciências da Universidade Estadual Paulista (UNESP), Marília, Brasil, depositadas em seu arquivo corrente, resultou em um trabalho conjunto de profissionais das áreas de Biblioteconomia e Arquivologia que buscam, nesse conjunto documental, identificar sua trajetória acadêmica e administrativa e facilitar 0 acesso às informações visuais.

\section{A gênese documental para identificação de acervos fotográficos: fundamentação teórica e metodológica sobre o tema}

Massas documentais acumuladas, sem nenhuma organização, são comuns em diversas instituições brasileiras. Na maioria das vezes, o único item conhecido é a instituição produtora. Dessa forma, preliminarmente à própria organização, pesquisas e estudos tornam-se necessários para recuperar a organicidade e as competências administrativas que geraram a documentação. Essa fase dentro dos estudos arquivísticos é conhecida como Identificação e permite estruturar e compreender funções, ações e atos determinantes para a elaboração e efetivação dos documentos. A identificação é fundamental para a organização de qualquer documentação arquivística, independente do tipo e/ou suporte documental.

Porém, em diversos momentos, ao nos depararmos com documentos fotográficos arquivísticos sem contextualização de sua produção e sem organização, tendemos, na maioria das vezes, a considerar o referencial da imagem como o determinante para a sua elaboração, assim o referente passa a ser o elemento "vivo" da fotografia, como se essa documentação houvesse sido produzida por e com este objetivo. A imagem fotográfica, como qualquer outro documento, compõe-se de diversos fatores e atributos e não de um único determinante.

Os autores Boadas, Casellas e Suquet (2001, p. 115) destacam a fase de Identificação como fundamental para a organização da documentação fotográfica:

La correcta identificación de los conjuntos - fondos o colecciones - es básica a nivel metodológico, ya que "cada documento forma parte de un todo estructurado del que, si se aísla, no tiene sentido y cuyo interés reside en la relación con los documentos que lo preceden y que lo siguen, en cuanto que viene a ser una instantánea dentro de una secuencia documental.

É necessário, tentarmos identificar todos os elementos formadores de uma fotografia, desde 
sua origem, intencionalidade, função, objetivos, operador da câmara, o tipo do material utilizado, a máquina, assim como filmes e lentes; ainda, seu processo de revelação, sua identificação, sua utilização, e finalmente sua guarda. Estes elementos que compõem a fotografia, se não forem identificados e preservados, serão eliminados ou esquecidos, restando-nos, quando muito, a imagem congelada e, sua leitura será falsa e incompleta, na medida em que temos parcialmente a informação documental.

Como um primeiro recurso torna-se fundamental resgatarmos a historicidade da fotografia, ou seja, situá-la historicamente no tempo e no espaço e sua produção institucional e/ou particular (Tagg, 2005, p. 9):

La imagen de archivo oficial es, de forma muy similar, aunque con propósitos diferentes, una imagen producida de acuerdo con determinadas normas formales y procedimientos técnicos de carácter institucionalizado que definen cuáles son las manipulaciones legítimas y las distorsiones permisibles, de modo que, en ciertos contextos, unos intérpretes más o menos hábiles y adecuadamente formados y autorizados pueden extraer conclusiones de ellas, sobre la base de convenciones históricamente establecidas. Es únicamente en este marco institucional donde adquieren peso y pueden imponerse significados que de otro modo podrían ser discutibles.

As instituições que, de alguma forma, produzem ou arquivam imagens fotográficas e as indexam adequadamente, preservam uma fonte histórica valiosa, passível de ser analisada e estudada pelas diferentes ciências humanas (Moreira Leite, 1998 p 39):

O fato de a fotografia ser um objeto perecível, sujeito a adulteração por fungos ou retoques, uso indevido ou envelhecimento, não reduz o seu valor documental; antes, amplia a necessidade de verificar as maneiras de selecionar, curar, recuperar e decodificar as informações que séries compostas de imagens podem fornecer ou sugerir.

Importante destacar que estamos discutindo a fotografia produzida por uma instituição, com função e atividades estabelecidas e não uma documentação recebida por compra ou doação, como ocorre em alguns centros e até mesmo arquivos. A procedência dos documentos determina as formas de organização e identificação, como bem aponta Antonia Herrera Heredia (1993, p. 11):

Así pues, la fotografía que encontramos en los depósitos documentales, ja sean archivos u otros centros, forman colecciones, procedentes de la actividad de un fotógrafo o de la afición coleccionista de un particular, entre éstas con frecuencia las postales, o bien forman parte de series archivísticas en las que equivalen a un trámite obligado.
Partindo deste princípio, que na maioria dos processos de organização de arquivos a fotografia é isolada de seu contexto original, porém, acreditando que sua produção é orgânica, estabelecemos as bases do que entendemos por documento de arquivo. Fundamentalmente, tomaremos a definição, segundo o Dicionário Brasileiro de Terminologia Arquivologia, que é "o conjunto de documentos que, independentemente da natureza ou do suporte, são reunidos por processo de acumulação ao longo das atividades de pessoas físicas ou jurídicas, públicas ou privadas, e conservados em decorrência de seu valor".

Balizando-nos por esse conceito, como devemos trabalhar as fotografias produzidas por essa instituição, reunidas e acumuladas com objetivos e funções específicas?

Em primeiro lugar, compreendermos a fotografia como resultado de uma função, uma intencionalidade, seja institucional ou particular. Apesar da imagem fotográfica muitas vezes não vir acompanhada de uma referência ou identificação textual situando a função daquele registro, devemos ter claro, que sempre haverá uma ação, um propósito original para a realização dessa atividade.

É essa ação original dentro de um contexto institucional é que deveria determinar o arquivamento do documento. Para isso, nesse primeiro momento não podemos nos ater só no registro imagético, mas buscarmos a historicidade e o contexto histórico de produção da(s) fotografia(s).

A gênese documental dessa produção, ou seja, a ação que determinou sua elaboração, juntamente com sua relação intrínseca com os demais documentos, são fundamentais e determinantes para a compreensão da efetivação e concretização específicas do documento. $O$ documento só existe a partir de uma ação, de uma vontade que se efetiva, se concretiza em uma materialidade. Portanto, o documento fotográfico de arquivo, como qualquer outro, tem sua criação estabelecida por normas e ações que determinam e definem sua estrutura final.

A autora Heloisa Liberalli Bellotto (2002, p. 36) discute a gênese dos documentos públicos e aponta que

Todo documento tem um autor ou autores, é dirigido a um indivíduo ou a uma coletividade, sua gênese está datada de um lugar (data tópica) e de um tempo (data cronológica) e se produz por alguma razão contida em seu texto [visual no caso analisado]. Há condições de aplicação e de sanção que dele também constam. A tramitação do documento, da sua origem à sua aplicação, depende da 
sua estrutura burocrática da época, do país e do direito que ali comanda a sociedade.

A compreensão das ações que determinaram a elaboração, efetivação, circulação e vínculos desse documento, ou seja, a gênese, é fundamental para entendermos sua inserção na produção documental institucional, a ser analisada e levantada em sua complexidade pela etapa de Identificação.

Como aponta o autor André Ancona Lopez (1996, p. 190), "os acervos de documentos imagéticos tendem, muitas vezes, a não revelar os princípios da organização arquivística, quando se valoriza o conteúdo informativo da imagem, em oposição ao seu contexto de produção enquanto documento arquivístico."

Para restabelecer a organicidade desta documentação, faz-se necessário um levantamento das funções e atividades realizadas pelo departamento e/ou seção que acumulou ou produziu as imagens, se possível a recuperação de organogramas a fim de historicizar a produção fotográfica realizada no período para identificarmos seus objetivos: os primeiros e reais solicitantes, a função original da fotografia, sua relação com outros documentos, inserção na rotina do órgão.

Ainda segundo os autores Joan Boadas, LluísEsteve Casellas e M. Àngels Suquet, essa ordem original de produção não pode ser desconsiderada, pois perderíamos as relações intrínsecas dessa documentação:

El orden que deberán tener finalmente las fotografías tendrá que ser por formatos, que es el más recomendable para garantizar su conservación, pero antes de iniciar cualquier actuación para la organización de un conjunto de fotografías se debe establecer el orden originario. Es decir, se tienen que determinar las agrupaciones mediante las cuales se halla dispuesta la documentación, operación que puede ser muy dificultosa en algunos casos y que siempre requiere un gran conocimiento del productor y una detenida observación del material documental. El orden originario pone en evidencia las relaciones recíprocas entre los documentos, derivadas de los fines y de los procedimientos que han presidido su nacimiento.

Há que ser observada as condições ideais para sua preservação e descrição, mas sua organicidade não pode ser desconsiderada. Dessa maneira, procuramos tratar a fotografia como qualquer outro documento, independente do suporte e de seu registro visual, já que, na sua produção (Kossoy, 1999 p. 129),

[...] conecta-se a uma realidade primeira que a gerou em algum lugar e época. Porém, perdendo-se os dados sobre aquele passado, ou melhor, não existindo informações acerca do referente que a originou, o que mais resta? Uma imagem perdida, sem identificação, sem identidade... sem história.

O tratamento dispensado a documentação fotográfica realizado pela maioria das instituições, que vêm na fotografia apenas seu uso imediato, não se preocupam com a permanência das informações primárias e originais daquele documento, mas privilegiam a conservação do suporte físico e a difusão dos registros imagéticos em banco de dados informatizados. A indexação muitas vezes, é feita de acordo com o assunto principal enfocado na fotografia e o que interessa é o uso da imagem e não do documento fotográfico.

Em relação a esse tratamento usual e cada vez mais comum nas instituições o autor André Ancona Lopez (2000, p. 17) observa que:

Muitas vezes, tem-se buscado, tanto para os procedimentos da classificação, como para a descrição documental, a inserção dos "conteúdos" de cada imagem em imensos bancos de dados, alimentados pela ilusão (quase cientificista) de que esta classificação detalhada é satisfatória para dar conta de todas (ou quase todas) as buscas possíveis; confunde-se análise documentária com organização arquivística. Deste modo, assume-se uma determinada interpretação da imagem como a única "leitura" correta, ou, pelo menos, como a mais capacitada para sintetizar, de modo quase universal, as imagens em questão. Ressalve-se que tal 'universalidade' não é assumida explicitamente, na maioria das vezes. Justifica-se a adoção de descritores como uma solução satisfatória, principalmente quando definem os documentos imagéticos de arquivo como especiais; ou seja, opta-se por uma solução tida como viável frente às especificidades daqueles documentos, nos quais os dados referentes à sua gênese não são explícitos.

Portanto, pautamo-nos por essa tentativa de explicitar, buscar e validar a gênese documental das fotografias de arquivo, produzidas e acumuladas por instituições públicas e/ou privadas, em detrimento a uma descrição exaustiva dos elementos imagéticos. Acreditamos que dessa forma, o documento fotográfico arquivístico preservará todas as suas informações documentais, sejam visíveis ou implícitas à sua própria elaboração.

\section{A gênese documental na identificação do acervo fotográfico da Faculdade de Filosofia e Ciências (FFC) da UNESP, Marília, Brasil}

A preocupação com o resgate, preservação e difusão da memória histórica e acadêmica de uma Universidade inserida no contexto de uma cidade do interior do Estado de São Paulo, Brasil, por meio de imagens fotográficas, fazem-se 
presentes na proposta em identificar e estudar a gênese documental do acervo de fotografias da Faculdade de Filosofia e Ciências (FFC) da Universidade Estadual Paulista (UNESP), Marília, Brasil, depositadas em seu arquivo corrente.

O acervo fotográfico da FFC tem ênfase nos acontecimentos importantes da trajetória acadêmica que abrange o período de 1959 a 1999: a instalação dos primeiros cursos de graduação no primeiro prédio ocupado, a realização das defesas públicas de mestrado e doutorado e outros eventos marcantes que modificaram 0 cenário de ensino, cultura e ciência no interior paulista.

Antes de integrar uma Universidade Estadual Paulista a partir de 1976, a história da atual Faculdade Filosofia e Ciências - Campus de Marília inicia-se no bojo de uma política governamental de interiorização do ensino superior em cidades do interior do Estado de São Paulo com a finalidade de promover seu desenvolvimento regional aliado à influência de centros de pesquisa e ensino. Assim, em 25 de janeiro de 1957, a Lei n.3781, aprovada pela Assembléia Legislativa do Estado e promulgada pelo governador, Sr. Jânio Quadros, criava a Faculdade de Filosofia, Ciências e Letras de Marília (antiga FAFI). No entanto, a existência legal da nova Faculdade não significou ainda a sua existência efetiva. Somente em 13 de janeiro de 1959 a Faculdade foi solenemente inaugurada e três dias depois, o Decreto Federal n.45.262 concedia inspeção prévia aos cursos a serem instalados, o que marcou oficialmente o início de suas atividades didáticas. Desde sua criação, a Faculdade de Filosofia e Ciências da UNESP Campus de Marília (FFC) tem se destacado como um espaço privilegiado de formação de futuros profissionais e de desenvolvimento de pesquisas na área de ciências humanas.

$O$ acervo fotográfico da FFC contém as imagens dos acontecimentos importantes dessa trajetória acadêmica no período de 1959 até 1999 com um total aproximado de 2220 fotos. Trata-se de um conjunto de documentos produzidos e acumulados pela Faculdade, no exercício de suas funções e atividades. Esse conjunto de fotografias possui as características de documentos arquivísticos; portanto, devem ser consideradas como parte do fundo, Faculdade de Filosofia e Ciências - UNESP, Campus de Marília.

A organização desse acervo fotográfico, em perspectiva biblioteconômica e arquivístiva, pretende resgatar sua gênese documental com a finalidade de identificar o contexto da trajetória acadêmica e administrativa da FFC e torná-lo acessível à comunidade como instrumento de recuperação, registro e guarda de documentos fotográficos.

Para uma organização e transferência desse material para o Arquivo Central da Universidade, procuramos manter a procedência dessa documentação a fim de não perdermos sua historicidade e formação. $O$ projeto iniciou-se com a descrição imagética, porém a manutenção da organicidade mostrou-se fundamental para que a função original dos documentos não se perdesse, em virtude da representação descritiva da imagem e, muito menos ainda, pela especificidade e fragilidade dos suportes materiais. Há que serem observadas as condições ideais para sua preservação e descrição, mas sua organicidade não pode ser desconsiderada.

O projeto, a partir desse momento, desmembrou-se em duas frentes de pesquisa: a primeira envolvida com as discussões de termos e métodos para representação descritiva e digitalização das fotografias; e a outra, com os levantamentos históricos, de legislação, depoimentos dos profissionais que trabalharam com os documentos para identificação da gênese documental.

Nesse sentido, o trabalho abordará as etapas para a identificação da gênese documental e sua importância na organização do fundo.

As fotografias do acervo fotográfico da FFC foram produzidas durante sua trajetória administrativa e acadêmica iniciada em 1959 e acondicionadas em álbuns fotográficos temáticos pela Direção da FFC ao longo dos anos. Esses álbuns possuíam denominações que foram determinadas em função dos acontecimentos acadêmicos e administrativos, como por exemplo, "Aula Inaugural", "Primeiro Vestibular" e etc. Essas denominações, em princípio, são características de uma organicidade de acontecimentos históricos que marcaram a trajetória acadêmica e administrativa da FFC. Os fotógrafos que produziram as fotografias são desconhecidos, porém, o fato desses álbuns terem sido conservados e mantidos junto à Direção da FFC nos leva a reconhecer os Diretores, em cada gestão administrativa, como os produtores (Quadro 1) e a FFC como responsável pela custódia do acervo fotográfico, cuja gênese determina sua identificação.

\begin{tabular}{ll}
\hline Periodo & Diretores e Vice Diretores: $^{\circ}$ \\
\hline $08 / 07 / 57-$ & Prof $^{\circ}$ Dr.José Querino Ribeiro \\
$31 / 12 / 57$ & \\
26/04/58- & Profo $^{\circ}$ Dr. Michel Pedro Sawaya \\
13/11/60 & $\begin{array}{l}\text { Diretor Assistente: Profo Antônio da } \\
\end{array}$ \\
Silveira Mendonça \\
13/11/60- & Profo $^{\circ}$ Dr. Massaud Moisés
\end{tabular}


21/03/62 Diretor Interino: Profo Ubaldo Martini Puppi

27/04/62- $\quad$ Prof ${ }^{\circ}$ Dr. Eurípedes Simões de Paula

20/04/65 Vice: Prof ${ }^{a}$ Dra. Olga Pantaleão

1965-1970 Profo Dr. José Querino Ribeiro

Vice: Profa Dra Olga Pantaleão

1970-1971 ProfoDr. Enzo Del Carratore

Vice: Ataliba de Castilho/ até junho

Vice: Prof ${ }^{a}$ Dra. Olga Pantaleão/em agosto

1971-1975 Profa Dra. Olga Pantaleão

Vice: Prof ${ }^{\circ}$ Dr. Domingos Viggiani

1975-1980 Profo Dr. Jubert Sanches Cibantos

Vice: Profo Dr. Vilmo Guimarães Melo

1980-1984 Profo Dr. Manoel Lello Belotto

Vice: Profo Dr. Alvanir de Figueiredo

1984-1988 Profo $^{\circ}$ Dr. Alvanir de Figueiredo

Vice: Profo Dr. Mário Masherpe de Assis

1988-1992 Profo Dr. Jayme Wanderley Gasparoto Vice: ProfaDra Yoshico Tanabe Mott

1992-1996 Profo Dr. Cândido Giraldez Vieitez Vice: Prof ${ }^{a} \mathrm{Dr}^{\mathrm{a}}$ Maria Isabel Leme Faleiros

1996-2000 Profo Dr. Antônio Geraldo Aguiar

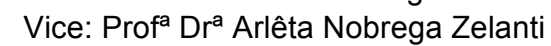

Quadro 1. Responsáveis pela Direção da Faculdade de Filosofia e Ciências (FFC)

Cada álbum compunha-se de um conjunto de fotografias armazenadas em seqüência da produção de cada fotografia formando uma seqüência visual do acontecimento o que consideramos fundamental para a compreensão da formação e organização do acervo fotográfico produzido pela FFC. Essa organização de cada álbum foi mantida e, na medida do possível, consideraram-se, inicialmente, as mesmas denominações para a identificação de 26 classes temáticas que são representativas do contexto histórico da FFC:

\begin{tabular}{ll}
\hline Códigos & Assuntos das Classes temáticas \\
\hline $\mathrm{AI}$ & Aula Inaugural \\
\hline $\mathrm{AF}$ & Antiga FAFI \\
\hline $\mathrm{BB}$ & Biblioteca \\
\hline $\mathrm{CCDH}$ & $\begin{array}{l}\text { Comemoração do V Centenário de D. } \\
\text { Henrique "O Navegador" }\end{array}$ \\
\hline $\mathrm{CF}$ & Construção da FAFI \\
\hline $\mathrm{CIC}$ & Congresso de Iniciação Cientifica \\
\hline $\mathrm{CL}$ & Curso de Literatura \\
\hline $\mathrm{CKB}$ & Conferência Kurt Baldinger \\
\hline $\mathrm{DT}$ & Doutoramento de 1955 e 1965 \\
\hline $\mathrm{FC}$ & Fotos da cidade (Marília) \\
\hline $\mathrm{FM}$ & Formaturas \\
\hline $\mathrm{IC}$ & Inauguração do Campus \\
\hline $\mathrm{IMH}$ & Inauguração do Museu de História \\
\hline JE & $\begin{array}{l}\text { Jornada de Estudos 28 e 29 de agosto } \\
\text { de 1991 }\end{array}$ \\
\hline
\end{tabular}

\begin{tabular}{ll}
\hline JP & Jubileu de Prata \\
\hline M40 & Memorial dos 40 anos (Faculdade) \\
\hline PF & Pedra Fundamental \\
\hline PV & Primeiro Vestibular \\
\hline SH & Semana de História \\
\hline SI & $\begin{array}{l}\text { Seminário Internacional "Globalização, } \\
\text { regionalismo e nacionalismo }\end{array}$ \\
\hline SIH & Simpósio de História \\
\hline TC & Transmissão de cargo Diretor/Vice, 20 \\
& de agosto de 1992 \\
\hline VG & Visita do Governador (Ney Braga) \\
\hline VNC & Venha nos conhecer \\
\hline VCJ & Visita do Cônsul do Japão \\
\hline XV JF & $\begin{array}{l}\text { XV Jornada de Filosofia e Teoria das } \\
\text { Ciências Humanas }\end{array}$ \\
\hline
\end{tabular}

Quadro 2. Gênese das Classes temáticas originais

Essa história é marcante para a identificação da proveniência de documentos originados em departamentos, atualmente inexistentes na $\mathrm{Fa}$ culdade de Filosofia e Ciências, como o "Departamento de História" e o "Departamento de Letras", que pertenciam, respectivamente, aos extintos Cursos de Graduação de História e de Letras. Os conjuntos documentais, no interior do fundo FFC, em nível de grupo e séries, são tratados como fechados, porque ambos os departamentos deixaram de produzir e acumular documentos no momento em que foram extintos. Assim, as classes temáticas "Comemoração do V Centenário de D. Henrique 'O Navegador'”, "Simpósio de História", "Semana de História", "Curso de Literatura" são representativas de um período em que existiam os Cursos de Graduação em História e em Letras.

Para a identificação da gênese documental das fotografias foram realizados levantamentos históricos em coleção de jornais da cidade, fontes históricas publicadas pela FFC, legislação e depoimentos dos profissionais que trabalharam com os documentos seguindo as etapas de: análise do contexto de produção da classe temática e análise do contexto de produção de cada fotografia.

Para as análises do contexto de produção da classe temática e de cada fotografia foi realizada pesquisa nos artigos dos jornais publicados em Marília que noticiaram os acontecimentos da FFC, bem como em fontes históricas publicadas pela FFC como: Anais da Faculdade de Filosofia, Ciências e Letras de Marília 1959-1962 (Faculdade..., 1969), o Guia da Faculdade (Faculdade..., 1962) e o "Histórico das gestões administrativas da Faculdade de Filosofia e Ciências (1959-1999)" (Fujita, 1999). 
As notícias dos jornais da cidade de Marília foram colecionadas desde o final dos anos 50 pela Direção e, depois, pela Biblioteca do Campus de Marília e formaram uma coleção encadernada dos cadernos de recortes de jornais que propiciou a pesquisa do contexto histórico de produção das fotografias considerando-se que a maioria fazia parte das notícias publicadas nos jornais. A existência da coleção encadernada dos recortes de jornais do período de 1958 a 1994 (Quadro 3) e as publicações da época facilitaram a identificação e confirmação da gênese documental do acervo fotográfico da FFC.

\begin{tabular}{lll}
\hline $1958 / 65$ & $1976 / 77$ & 1987 \\
\hline $1965 / 66$ & 1977 & $1988-3 \mathrm{v}$ \\
\hline $1966 / 68$ & $1976 / 79$ & $1989-4 \mathrm{v}$ \\
\hline 1970 & 1980 & $1990-4 \mathrm{v}$ \\
\hline 1971 & 1981 & $1991-5 \mathrm{v}$ \\
\hline 1972 & 1982 & $1992-4 \mathrm{v}$ \\
\hline 1973 & 1983 & 1993 \\
\hline 1974 & 1984 & $1994-2 \mathrm{v}$ \\
\hline
\end{tabular}

Quadro 3. Cronologia dos Cadernos de recortes de jornais da cidade (com notícias da FFC)

Exemplo é a fotografia "Ato religioso - PF 07" da classe temática Pedra Fundamental. A princípio a fotografia foi interpretada como Discurso do Senhor Antonio Barreto de Carvalho devido este Senhor estar olhando para baixo no sentido do material que segura em suas mãos, mas foi descartada já que parece não estar proferindo um discurso. A $2^{\mathrm{a}}$ interpretação levou em consideração a presença do bispo de Marília Dom Hugo Bressane (à esquerda) na fotografia que, possivelmente, estaria presente na cerimônia de lançamento da pedra fundamental celebrando cerimônia religiosa.

Com essa foto é possível esclarecer a localização do tema da classe temática "Pedra fundamental" no caderno de recortes da FFC levando-se em consideração as informações sobre referência do artigo, evento/título, local, data, pessoas citadas e resumo contidos em um roteiro para identificação de dados em notícias de jornais (Anexo $A$ ).

Nessas fontes procuramos dados informacionais sobre o evento, que possam localizá-lo no tempo e no espaço. Foi dessas fontes que conseguimos valiosas informações sobre o contexto histórico de produção da fotografia que contribuíram para a identificação da gênese documental. Localizaram-se vários recortes de jornais sobre o acontecimento registrado na fotografia (Figura 1) que possibilitaram a análise de con- teúdo e a descrição resumida do contexto histórico de produção. Como exemplo, a notícia de jornal transcrita abaixo, relata o evento registrado na fotografia (FAFI, 1973):

Em entrevista coletiva que terá lugar amanhã [01/02/1973], às 10 horas, na Faculdade de Filosofia e Ciências e Letras de Marília, a Diretora, Profa Olga Pantaleão, falará à imprensa Mariliense sobre as condições em que será construído o novo prédio onde funcionará o referido estabelecimento de ensino. O prédio da faculdade será um moderno conjunto arquitetônico, com amplas instalações para a diretoria, professores, funcionários, salas de reuniões, de aulas e laboratórios de pesquisa, biblioteca, salão nobre e diversas outras divisões. O lançamento da pedra fundamental do edifício será realizado na próxima sexta-feira [02/02/1973] às 17 horas, em terreno localizado às margens da rodovia Marília-Assis, proximidades do trevo que dá acesso a Tupã desapropriado pela Prefeitura e doado ao Estado.

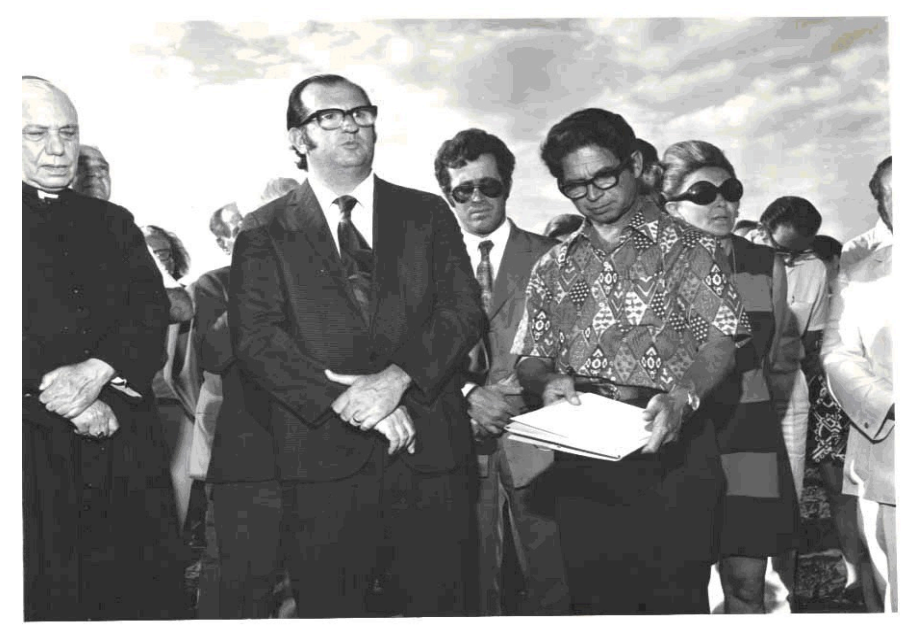

Figura 1. Fotografia PF07- Série: Inauguração do Campus - Ato religioso, Marilia, SP, 02/02/1973. Cerimônia de lançamento da pedra fundamental; Pessoas em pé: Dom Hugo Bressane de Araújo, Luiz Rossi, Luiz Barreto, Antonio Barreto de Carvalho, Josefina Chaia Pereira.Fonte: Memorial Fotográfico da FFC.

No caso das imagens sobre as quais não se conseguiu obter dados a respeito do conteúdo temático, tornou-se necessário ir a campo investigar em fontes vivas (pessoas que possam reconhecer e identificar a imagem, como exprofessores ou ex-funcionários da UNESP). Quando identificadas o suficiente, as informações referentes à imagem fotográfica são transferidas para os campos do Roteiro para identificação de dados em notícias de jornais (Anexo A), onde também é elaborado um resumo detaIhado da imagem, o qual irá servir de guia ou de fonte de contexto histórico de produção na análise de cada fotografia da classe temática. As- 
sim, logo que identificados os atributos morfológicos, conteúdo e contexto de cada imagem, encerra-se e preenche-se o roteiro para identificação dos dados em fotografias (Anexo B), concluindo-se o processo de identificação da imagem fotográfica.

$\mathrm{Na}$ fase de análise do contexto de produção de cada fotografia são coletadas informações das notícias publicadas em jornais da cidade que foram colecionadas como recortes de jornais pela FFC, considerados a principal fonte de informação e, se necessário, depoimentos detaIhados dos antigos funcionários e docentes. Com as informações coletadas na análise dos artigos de jornais, cada fotografia é analisada seguindo, também, um roteiro pré-estabelecido que inclui análise externa e análise de conteúdo composta de análise morfológica e análise temática em perspectiva biblioteconômica (Anexo B). Para as fotografias com pessoas, usamos a silhuetagem, ou seja, delinear o contorno das pessoas e um número identificador.

A análise de conteúdo consiste da análise morfológica (forma do conteúdo), do conteúdo temático (tema ou assunto) e do conteúdo icônico (descrição da imagem visual) e permite que as fotografias sejam organizadas por assuntos específicos para melhor acesso e recuperação. Com a análise de conteúdo será possível dinamizar as funções de memória social e acadêmica do arquivo de fotografias, realizando a divulgação através de exposições temáticas melhor elaboradas, bem como o resgate, a qualquer tempo, da memória acadêmica para diversos fins.

Com a pesquisa em recortes de jornais de Marília, fontes históricas publicadas e entrevistas com funcionários e docentes que participaram dos acontecimentos registrados nas fotografias foi possível revelar uma profícua atividade acadêmica da Faculdade de Filosofia e Ciências, permeada de acontecimentos culturais e científicos assistidos pela comunidade científica brasileira e estrangeira no entorno e contexto de Marília, uma cidade do interior do Estado de São Paulo. Além disso, propiciou uma reformulação e detalhamento das 26 classes temáticas iniciais em 57 classes temáticas conforme Quadro 3 (Apêndice A).

\section{Considerações finais}

$\mathrm{O}$ tratamento dispensado às fotografias da $\mathrm{Fa}$ culdade de Filosofia e Ciências até esse momento, pautou-se pela recuperação dos contextos histórico e institucional para a identificação dos eventos e atividades registrados nas fotografias acondicionadas originalmente em ál- buns. Nessa etapa, as fontes disponíveis desde a legislação, recortes de jornais e até entrevistas com antigos funcionários foram realizadas. Todo esse processo visava, num primeiro momento, agilizar a disponibilidade das imagens aos pesquisadores, devido a sua relevância para a memória institucional.

Ao iniciarmos a etapa de identificação arquivística, além desses levantamentos, iremos analisar, ou caso não exista, teremos que elaborar, o organograma da faculdade, identificando departamentos e seções e principalmente as atividades desempenhadas por eles. Dessa forma, poderemos perceber a inserção dessa produção fotográfica no amplo contexto documental da instituição, relacionando-a com documentos de diferentes suportes, mas que se ligam organicamente, já que produzidos com e para as mesmas funções.

Levantaremos as determinações e motivos pelos quais as fotografias foram acondicionadas em álbuns, o setor em que foram guardadas e onde estão as demais fotografias, já que as imagens em álbuns são normalmente selecionadas; foram profissionais contratados ou eram funcionários da própria Faculdade que registraram os eventos? Esses questionamentos pautarão nossas pesquisas, para buscarmos identificar as lacunas ainda existentes a fim de compreender o processo arquivístico de criação desses documentos fotográficos.

\section{Notas}

(1) Coordenado pelas Professoras Mariângela Spotti Lopes Fujita e Telma Campanha de Carvalho Madio

(2) Relação das gestões acadêmicas da Faculdade de Filosofia e Ciências extraída de Fujita (1999).

\section{Referencias}

Acervo - Revista do Arquivo Nacional Rio de Janeiro: Arquivo Nacional. (1993) Rio de Janeiro, v. 6 n.1-2, jan./dez. 1993.

Bellotto, Heloísa Liberalli. (2002) Como fazer análise diplomática e análise tipológica de documento de arquivo. São Paulo: Arquivo do Estado, Imprensa Oficial do Estado, 2002.

Benjamin, Walter. (1985) Obras escolhidas: Magia e técnica, arte e política. São Paulo: Ed. Brasiliense, 1985.

Boadas, Joan; Casellas, Lluís-Esteve; Suquet, M. Àngels. (2001) Manual para la gestión de fondos y colecciones fotográficas. Girona: CCG ediciones, Centre de Recerca i Difusió de la Imatge (CRDI), 2001.

Burgi, Sérgio. Introdução à preservação e conservação de acervos fotográficos: técnicas, métodos e materiais. Rio de Janeiro: Infoto/Funarte, 1988.

Dicionário de terminologia arquivística. (1996) São Paulo: Aab-Sp; Secretaria de Estado da Cultura, 1996. 
Fafi começa a construir amanhã. (1973) Correio de Marília, 31 de janeiro de 1973.

Filippi, P. ; Lima, S. F. ; Carvalho, V.C. (2002) Como tratar coleções de fotografias. São Paulo: Arquivo do Estado: Imprensa Oficial do Estado, 2002.

Fujita, M. S. L. (1999) Histórico das gestões administrativas da Faculdade de Filosofia e Ciências (1959-1999). Marília: Departamento de Ciência da Informação, Faculdade de Filosofia e Ciências, 1999. (Relatório de pesquisa)

Fujita, Mariângela Spotti Lopes et. al. (2004) A memória acadêmica em imagens fotográficas: representação documentária e digitalização de fotografias. In:Seminário Nacional de Bibliotecas Universitárias, 13., 2004, Natal. Anais... Natal, 2004. 1 CD-ROM.

Heredia Herrera, Antonia. (1993) La fotografía y los archivos. // Foro Iberoamericano de la Rábida. Jornadas Archivísticas, 2, 1993, Palos de la Frontera. La fotografía como fuente de información. Huelva: Diputación Provincial, 1993.

Kossoy, Boris. (1999) Realidades e ficções na trama fotográfica. Cotia (SP): Ateliê, 1999.

Lopez, André Porto Ancona. (2000) As razões e os sentidos: finalidades da produção documental e interpretação de conteúdos na organização arquivística de documentos imagéticos. Tese de Doutoramento. São Paulo: Programa de Pós-Graduação em História Social da FFLCHUSP, 2000.

Lopez, André Porto Ancona. (1999) Documentos imagéticos de arquivo: uma tentativa de utilização de alguns conceitos de Panofsky. Sinopses, São Paulo :31 (jun. 1999) 49-55.

Lopez, André Porto Ancona. (1996) Organização arquivística de documentos imagéticos e pesquisa histórica. Cadernos de Metodologia e Técnica de Pesquisa, Maringá (PR), 7 (1996) 189-198.
Lopez, André Porto Ancona. (1999) Tipologia documental de partidos e associações políticas brasileiras. São Paulo: História Social Usp; Loyola, 1999. (Série Teses).

Manual para catalogação de documentos fotográficos. (1997) 2. ed. Rio de Janeiro: FUNARTE: Fundação Biblioteca Nacional, 1997.

Manual para el uso de archivos fotográficos: fuentes para la investigación y pautas de conservación de fondos documentales fotográficos. (1997) Santander: Universidad de Cantabria; Madrid: Ministerio de Educación y Cultura, 1997.

Mauad, Ana Maria. (1996) Através da imagem: fotografia e história interfaces. Tempo, Rio de Janeiro, 1: 2 (1996) 73-98.

Moreira Leite, Míriam L., FIELDMAN-BIANCO, Bela (Orgs). (1998) Desafios da Imagem: fotografia, iconografia e vídeo nas ciências sociais. Campinas: Papirus, 1998

São Paulo (Cidade). (1992) Secretaria Municipal de Cultura. Guia preliminar do Arquivo de Negativos. São Paulo: Departamento do Patrimônio Histórico, 1992.

São Paulo (Cidade). (1992) Secretaria Municipal de Cultura. O acervo fotográfico do Departamento do Patrimônio Histórico: processamento técnico e informatização. São Paulo: Departamento do Patrimônio Histórico, 1992.

Smit, Johanna W. (coord.). (1987) Análise documentária: a análise da síntese. Brasília: IBICT, 1987.

Sontag, Susan. (1981) Ensaios sobre a Fotografia. Rio de Janeiro: Arbor, 1981.

Tagg, John. (2005) El peso de la representación. Barcelona: Gustavo Gili, 2005

Valle Gastaminza, Félix del (Org.) (1999) Manual de documentación fotográfica. Madrid: Editorial Síntesis, 1999.

\section{Apêndice}

\begin{tabular}{|c|c|}
\hline $\begin{array}{l}\text { Códigos das classes } \\
\text { temáticas }\end{array}$ & Assuntos das classes temáticas \\
\hline $\mathrm{AF}$ & Antiga FAFI (3 pastas) \\
\hline AF-XV & Aniversário da Faculdade \\
\hline $\mathrm{Al}(61)$ & Aula inaugural (1961) \\
\hline $\mathrm{Al}(62)$ & Aula inaugural (1962) \\
\hline $\mathrm{Al}(63)$ & Aula inaugural (1963) \\
\hline $\mathrm{Al}(72)$ & Aula inaugural (1972) \\
\hline BB & Biblioteca \\
\hline $\mathrm{CCDH}$ & Comemoração do V Centenário de D. Henrique "O navegador" \\
\hline $\mathrm{CCO}$ & Coral Canto dos Olhos \\
\hline CEDHUM & CEDHUM \\
\hline $\mathrm{CF}$ & Construção da Faculdade \\
\hline CKB & Conferência Kurt Baldinger \\
\hline CLP & Curso de leitura de Poesia Modernista \\
\hline DT (55) & Doutoramento 1955 \\
\hline DT (65) & Doutoramento 1965 \\
\hline EAF & Escola de Arte da FAFI \\
\hline EMX & Encontro com Mestre Xidiel (em andamento) (2 pastas) \\
\hline FRM (63) & $1^{\text {a }}$ Formatura (1963) \\
\hline FRM (82) & Formatura de 1982 \\
\hline FRM (89) & Formatura de 1989 \\
\hline
\end{tabular}




\begin{tabular}{|c|c|}
\hline FRM (91) & Formatura de 1991 \\
\hline IB & Inauguração da Biblioteca \\
\hline IC & Inauguração do Campus \\
\hline IF & Inauguração FAFI \\
\hline $\mathrm{IFi}$ & FAFI - Instalações físicas \\
\hline IMH & Inauguração Museu História \\
\hline JCS-II & II Jornada de Ciências Sociais: Caio Prado Jr. \\
\hline JCS-IV & IV Jornada de Ciências Sociais: Octávio lanni \\
\hline JFCH-XV & Jornada de Filosofia e Teoria das Ciências Humanas: Colóquio Oswaldo Porchat \\
\hline JP & Jubileu de Prata \\
\hline LA & Laboratórios \\
\hline $\mathrm{M}(40)$ & Memória dos 40 anos da Faculdade \\
\hline $\mathrm{PC}$ & Prédio do Campus \\
\hline PF & Pedra Fundamental \\
\hline PLB & Ciclo de conferências: Panorama da literatura \\
\hline $\mathrm{RP}$ & Reuniões de professores \\
\hline SF & Semana da Faculdade (s/data) \\
\hline SFDB & Departamento de Biblioteconomia (1987) \\
\hline SF-IV & Semana da Faculdade (1962) \\
\hline SF-IX & Semana da Faculdade (1967) \\
\hline SF-V & Semana da Faculdade (1963) \\
\hline SF-XXII & Semana da Faculdade (1981) \\
\hline SF-XXIII & Semana da Faculdade (1987) \\
\hline SF-XXX & Semana da Faculdade (1989) \\
\hline SF-XXXII & Semana da Faculdade (1991) \\
\hline $\mathrm{SI}$ & II Seminário Internacional (1995) - "Globalização, regionalização e nacionalismo" \\
\hline SI & Seminário Internacional - "Liberalismo e socialismo: velhos e novos paradigmas" \\
\hline $\mathrm{SIH}$ & Simpósio de História \\
\hline $\mathrm{TC}$ & Transmissão de cargo/vice (1992) \\
\hline TEC & Tecelagem \\
\hline $\mathrm{V}$ & Vestibular \\
\hline VG & Visita do Governador Ney Braga \\
\hline VNC & Venha nos conhecer - s/ data \\
\hline VNC (89) & Venha nos conhecer (1989) \\
\hline VNC (90) & Venha nos conhecer (1990) \\
\hline VNC (91) & Venha nos conhecer (1991) \\
\hline VVCJ & Visita do Vice-consulado do Japão \\
\hline
\end{tabular}

Quadro 3. Detalhamento das classes temáticas originais

\title{
Anexo A. Roteiro para identificação de dados em notícias de jornais
}

\author{
1 - Referência \\ 2 - Evento/título \\ 3 - Local \\ 4 - Data \\ 5 - Pessoas citadas \\ 6 - Resumo
}

Anexo B. Roteiro para identificação dos dados em fotografias

\section{Dados de controle \\ 1.1 Número de identificação da fotografia: \\ 1.2 Data da fotografia (dia/mês/ano): \\ 1.3 Classe temática: \\ 2. Análise externa}




\subsection{Título:}

2.2 Estado de conservação: ( )ótimo ( )bom ( )ruim ( )péssimo

2.3 Dimensão:

2.4 Identificação de carimbos, etiquetas, dedicatórias e anotações (descrever)

\section{Análise de conteúdo}

3.1 Análise morfológica

3.1.1 Tipo de iluminação:

( ) noite ( ) dia

( ) luz artificial ( )natural

3.1.2 Posição da luz: ( ) contraluz ( ) luz lateral ( ) luz central ( ) luz baixa ( ) sobreposição

3.1.3 Valores de enquadramento: ( ) plano geral, ( ) plano médio, ( ) primeiro plano, ( ) plano detalhado

3.1.4 Coloração: ( ) colorida, ( ) branca/preta, ( ) sépia

3.2 Conteúdo temático

3.2.1 Espaço geográfico (descrição do lugar) - (onde?)

- Continente, país, região, província, localidade, bairro, distrito, rua, edifício.

3.2.2 Descritor cronológico (tempo histórico) - (quando?)

- datas, décadas, períodos históricos, horário.

3.2.3 Descritores temáticos

- (Quem?): Pessoas: sexo, idade, ocupação, raça, traje, postura, nome (se souber)

- (O QUE?)

- Elementos naturais:

Exemplo : praias, bosque, campo, nuvens, água, montanhas, árvores, vales.

- Elementos artificiais:

Exemplo : casa, carro, cadeira, monumentos, objetos.

- (Como?) - Ações

- Cenas da vida, tipos, atividades que realizam

- (Por que, para que) - Resumo descritivo-narrativo, 